\section{Successful Metronidazole Desensitization Using Modified Oral Protocol}

Received: December 17, 2015; Accepted: December 24, 2015; Published: December 28, 2015

Keywords: Allergen, Airborne allergen, Allergic Rhinitis, Bronchial Asthma, Skin prick test

\section{Short Communication}

Trichomoniasis is the most prevalent nonviral sexually transmitted infection in the United States and affects over $11 \%$ of women over the age of 40 [1]. Metronidazole and tinidazole are the only medications that are recommended by the Centers for Disease Control for the treatment of trichomoniasis1. Alternative therapies are not standardized and limited in efficacy [2]. Case reports suggest that there is cross-reactivity between metronidazole and tinidazole [3]. The body of literature describing metronidazole hypersensitivity is scarce and to date, the incidence is unknown. Skin-prick testing to metronidazole is not validated. Three metronidazole desensitization protocols have been described, including one intravenous 3 and two oral protocols [4,5]. In 2008, the Centers for Disease Control and Prevention published a study documenting a total of 127 patients with suspected metronidazole hypersensitivity, among whom 15 patients underwent metronidazole desensitization2. Among those 15 patients, 7 patients underwent a 14-dose intravenous protocol3 and 8 patients underwent an 8-dose oral protocol5. All 15 patients achieved infection cure. More recently, a 12dose modified oral desensitization protocol was described by Gendelman and colleagues in 2014.

We present the case of a 48 year old African-American female with diagnosis of vaginal trichomoniasis who had been untreated for 9 months due to a history of metronidazole hypersensitivity. She had received oral metronidazole ( 8 tablets, presumably a total of $2 \mathrm{gm}$ ) approximately 30 years ago for treatment of vaginal trichomoniasis. Within 1-2 hrs, she developed hives, "distended veins," and shortness of breath. She called paramedics and was treated in the emergency department for presumed anaphylaxis. Since then, she has avoided the drug. She was referred for Allergy/Immunology evaluation of metronidazole sensitivity. At her initial evaluation, her past medical history was significant for hypertension, depression, tobacco exposure and a diagnosis of "bronchitis." She described dyspnea and wheeze with exertion and occasional albuterol use. The patient had no previous respiratoryrelated emergency department visits or hospitalizations.

The patient was admitted to the intensive care unit for oral metronidazole desensitization. She was pretreated with

\author{
Shijun Cindy Xi, \\ Lori P Banka, \\ Salima Thobani, \\ Marillyn Li, \\ Kenny YC Kwong and \\ Lyne Scott
}

\author{
Division of Allergy and Immunology, \\ Los Angeles County and University of \\ Southern California Medical Center, USA
}

Corresponding author: Shijun Cindy Xi

xicindy@gmail.com

Division of Allergy and Immunology, Los Angeles County and University of Southern California Medical Center, USA.

Tel: 6178529714

Citation: Cindy XS, Banka LP, Thobani S, et al. Successful Metronidazole Desensitization Using Modified Oral Protocol. Insights Allergy Asthma Bronchitis. 2015, 1:2.

prednisone $40 \mathrm{mg}$ oral daily 2 days prior to and on the day of desensitization. Antihistamines were discontinued one week prior to admission. Vital signs, cardiac and pulmonary examination were within normal limits. FEV1 was $80 \%$ of predicted. Skin prick test was performed to metronidazole $2 \mathrm{mg} / \mathrm{mL}$, glycerin control and histamine control. Glycerin control and metronidazole were negative and histamine was positive. Following skin prick testing, she received pretreatment with oral diphenhydramine $50 \mathrm{mg}$. She then underwent an oral, 12-dose modified protocol (Table 1) as described by Gendelman et al. Doses were given at 30-minute intervals and vital signs were checked every 30 minutes. She tolerated the protocol without any reactions, was observed for $4 \mathrm{hrs}$ after completion of the protocol, and was discharged home the same day.

In determining the optimal management strategy for this patient, we weighed a number of "low-risk" as well as "high-risk" factors. The patient's reaction to metronidazole was remote, so theoretically, IgE specific to metronidazole should have waned over time. However, her reaction was severe and she had a history consistent with chronic pulmonary disease that would make her at risk for a more severe reaction. Given the paucity of literature 
Table 1 Modified oral desensitization protocol (Gendelmen et al.).

$\begin{array}{lc}\text { Dose } 1 & 0.0025 \mathrm{mg} \\ \text { Dose } 2 & 0.025 \mathrm{mg} \\ \text { Dose } 3 & 0.25 \mathrm{mg} \\ \text { Dose } 4 & 2.5 \mathrm{mg} \\ \text { Dose } 5 & 5 \mathrm{mg} \\ \text { Dose } 6 & 10 \mathrm{mg} \\ \text { Dose } 7 & 25 \mathrm{mg} \\ \text { Dose } 8 & 50 \mathrm{mg} \\ \text { Dose } 9 & 100 \mathrm{mg} \\ \text { Dose } 10 & 250 \mathrm{mg} \\ \text { Dose } 11 & 500 \mathrm{mg} \\ \text { Dose } 12 & 1000 \mathrm{mg}\end{array}$

on metronidazole hypersensitivity and lack of predictability of skin prick testing; we proceeded cautiously by performing the modified oral desensitization protocol in a monitored setting. We hope that as the body of literature grows on metronidazole hypersensitivity (and drug hypersensitivity in general), we may develop standardized testing to help guide management. In the meantime, we provide another example of successful treatment with the modified oral metronidazole desensitization protocol. 


\section{References}

1 Centers for Disease Control and Prevention Sexually Transmitted Diseases Treatment Guidelines, 2015. MMWR Recomm Rep. 64: 72-75.

2 Helms DJ, Mosure DJ, Secore WE, Workowski KA (2008) Management of trichomonas vaginalis in women with suspected metronidazole hypersensitivity. Am J Obstet Gynecol 198: 370.e1-7.

3 Pearlman MD, Yashar C, Ernst S, Solomon W (1996) An incremental dosing protocol for women with severe vaginal trichomoniasis and adverse reaction to metronidazole. Am J Obstet Gynecol 174: 934-936.

4 Gendelman SR, Pien LC, Gutta RC, Abouhassan SR (2014) Modified oral metronidazole desensitization protocol. Allergy Rhinol 5: e66-e69.

5 Kurohara ML, Kwong FK, Lebherz TB, Klaustermeyer WB (1991) Metronidazole hypersensivity and oral desensitization. J Allergy Clin Immunol 88: 279-80. 